\title{
Prevention of Ulcer Recurrence After Eradication of Helicobacter pylori: A Prospective Long-term Follow-up Study
}

\author{
RENÉ W. M. VAN DER HULST,* ERIK A. J. RAUWS,* BIRCAN KÖYCÜ,* JOSBERT J. KELLER,* \\ MARCO J. BRUNO,* JAN G. P. TIJSSEN, ${ }^{\star}$ and GUIDO N. J. TYTGAT* \\ Departments of *Gastroenterology and Hepatology and ${ }^{\dagger}$ Clinical Epidemiology, Academic Medical Center, Amsterdam, The Netherlands
}

Background \& Aims: Short-term follow-up studies show lower relapse rates of duodenal and gastric ulcers after successful Helicobacter pylori eradication. The aim of this study was to determine the long-term outcome of ulcer disease after successful $\boldsymbol{H}$. pylori eradication. Methods: We prospectively studied the long-term effect of $\boldsymbol{H}$. pylori eradication on ulcer recurrence rates in patients after endoscopically proven healing of duodenal or gastric ulcers between 1984 and 1995. Patients using nonsteroidal anti-inflammatory drugs (NSAIDs), aspirin, or maintenance antisecretory therapy were excluded. $H$. pylori infection was assessed by culture and histopathology of gastric biopsy specimens. After endoscopically proven ulcer healing and successful $H$. pylori eradication, 186 patients with ulcers underwent elective endoscopy every 3 months during the first year of follow-up and were advised to contact us at symptom recurrence. Thereafter, 96 patients were available for elective half-yearly endoscopies. The 89 patients who did not choose to undergo the repeated endoscopies were asked about symptom recurrence and to undergo elective endoscopy in 1995. Results: Successful $H$. pylori eradication was achieved in 141 patients with duodenal ulcers and 45 patients with gastric ulcers. None of the $141 \mathrm{H}$. pylori-eradicated patients with duodenal ulcers had an ulcer relapse after follow-up of 367 patient-years. Ulcer relapses were also absent in the $45 \mathrm{H}$. pylori-eradicated patients with gastric ulcers after 113 patient-years of follow-up. Conclusions: Excluding patients taking aspirin or NSAIDs, recurrence of duodenal or gastric ulcers is completely prevented after successful $H$. pylori eradication for up to 9.8 years.

$\mathrm{T}$ he pathogenic role of Helicobacter pylori in chronic active gastritis and its association with duodenal ulcer disease in $95 \%-99 \%$ of patients are well established. ${ }^{1-3}$ Therefore, the 1994 National Institutes of Health Consensus Development Conference recommended eradication of $H$. pylori in all patients with documented peptic ulcer disease. ${ }^{4}$

Several studies of 1-year follow-up in patients with duodenal ulcers indicate that eradication of $H$. pylori dra- matically reduces ulcer relapse rates. ${ }^{2-24}$ The few studies in patients with gastric ulcers had similar findings. ${ }^{2,25-29}$ Only a few studies have followed up on patients with duodenal ulcers for more than 1 year. ${ }^{30,31}$ All these studies report ulcer relapses $(3 \%-22 \%)$ despite successful $H$. pylori eradication. Factors clarifying the variance in study results include the varying end points: absence of documented initial ulcer disease and ulcer healing; unknown H. pylori status at the time of ulcer relapse or at the conclusion of the study ${ }^{14,17,18,25}$; and the assessment of cure of the infection by $H$. pylori clearance instead of $H$. pylori eradication, a difference leading to high rates of H. pylori recrudescence and ulcer relapse rates. ${ }^{5,9,12,26}$ Moreover, the use of nonsteroidal anti-inflammatory drugs (NSAIDs), aspirin, or maintenance histamine 2 -receptor antagonist $\left(\mathrm{H}_{2} \mathrm{RA}\right)$ may influence reported ulcer relapse rates. To obtain more detailed information on the clinical outcome in patients with peptic ulcers after prolonged follow-up, we conducted a prospective study with scheduled follow-up endoscopies every 3 months for the first year, after initial ulcer healing (endoscopy) and $H$. pylori eradication (culture and histology) was confirmed. Thereafter, elective half-yearly endoscopies were performed in half of the patients. Patients who declined another series of repetitive endoscopies were asked to undergo elective endoscopy at conclusion of the study. Patients on aspirin, NSAID, or maintenance $\mathrm{H}_{2} \mathrm{RA}$ therapy were excluded.

\section{Materials and Methods}

\section{Source Population}

Consecutive dyspeptic patients referred for diagnostic upper gastrointestinal endoscopy with endoscopically proven active peptic ulcers (either duodenal ulcer or gastric ulcer) and proven $H$. pylori infection were included in the study. All were enrolled between 1984 and 1994 and also participated in sequential $H$. pylori eradication trials. Patients willing to

\footnotetext{
Abbreviations used in this paper: CBS, colloidal bismuth subcitrate; $\mathrm{H}_{2} \mathrm{RA}$, histamine ${ }_{2}$-receptor antagonist.

(C) 1997 by the American Gastroenterological Association 0016-5085/97/\$3.00
} 


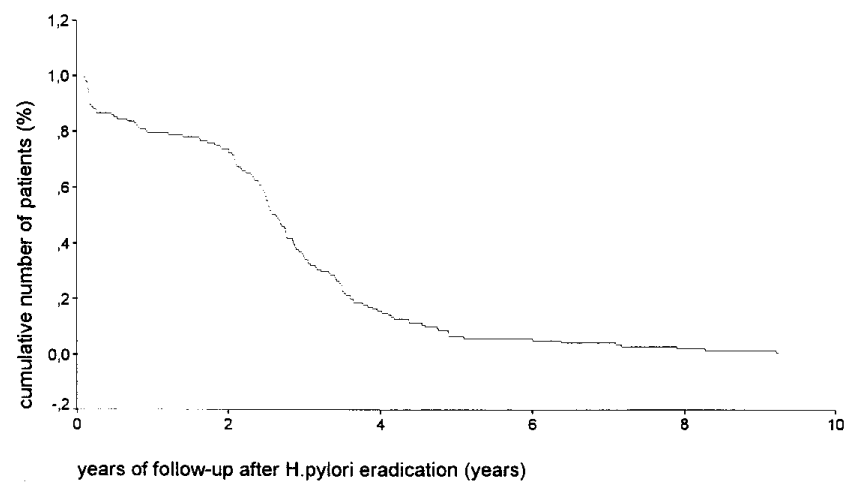

Figure 1. Cumulative number of patients with duodenal ulcers per year of follow-up after apparently successful $H$. pylori eradication.

undergo repeated elective follow-up endoscopies with biopsies were followed up for a prolonged period. Patients were excluded if they were on maintenance acid-suppressive therapy or if they used aspirin or NSAIDs. Patients were excluded if they had undergone previous gastric surgery; were alcohol abusers; had cardiac, pulmonary, liver, or kidney disease; or were on anticoagulant therapy.

\section{H. pylori Assessment}

H. pylori assessment was performed before and 4-6 weeks after completion of each $H$. pylori eradication attempt and at all endoscopies performed during follow-up. Four gastric antrum biopsy specimens were routinely taken for culture $(\mathrm{n}=2)$ and histopathology $(\mathrm{n}=2)$. Corpus biopsy specimens for culture $(n=2)$ and histopathology $(n=2)$ were taken when proton pump inhibitors became part of therapy.

Formalin-fixed gastric biopsy specimens were stained with $\mathrm{H} \& \mathrm{E}$ for histopathologic examination, and two histopathologists examined the preparations independently. If the stain revealed no microorganisms, no additional special staining was performed. Culture of gastric biopsy specimens was performed on selective blood agar plates (no. 2 Columbia agar; Oxoid Ltd., London, England, supplemented with horse blood, 5\% by volume, and Skirrow supplement; Oxoid), under microaerophilic conditions. Gram-negative and oxidase-, catalase-, and urease-positive spiral, curved rods were identified as H. pylori. ${ }^{32}$ The microbiologist and histopathologists performing the tests were unaware of each others' results. $H$. pylori infection was present if results of culture and/or histopathological assessment were positive. Cure of $H$. pylori infection was defined as absence of $H$. pylori in both culture and histopathological examination.

\section{Administered Therapies}

Once an active ulcer was diagnosed, acid-suppressive therapy was administered until the ulcer was completely healed as confirmed by endoscopy. After complete ulcer healing, acidsuppressive therapy was discontinued, and $\mathrm{H}_{2} \mathrm{RA}$ was used only on demand.

After documented ulcer healing, an $H$. pylori eradication regimen was started. Eradication therapies have varied over the years, consisting of either bismuth monotherapy (colloidal bismuth subcitrate [CBS]); bismuth dual therapy (CBS-metronidazole/CBS-amoxicillin); bismuth triple therapy (CBS-amoxicillin-metronidazole/CBS-tetracycline-metronidazole); or proton pump inhibitor dual therapy (omeprazole-amoxicillin/ omeprazole-clarithromycin). The administration of a certain therapy depended on the advised therapy regimen at that time. Patients underwent sequential $H$. pylori eradication attempts until the infection was cured.

\section{Study Population}

Follow-up scheme. After complete healing of the ulcer, discontinuation of acid-suppressive therapy (only on-demand use was allowed), and successful $H$. pylori eradication, all patients were followed up by endoscopy at 3-month intervals for the first year. All patients were instructed to contact the responsible physician if dyspeptic symptoms recurred, and these patients were permitted to resume taking $\mathrm{H}_{2} \mathrm{RA}$ until endoscopy was performed (within 2 days).

After the first year, elective follow-up endoscopies were performed half-yearly in those patients willing to undergo these sequential examinations. The remaining patients were contacted again in 1995 to assess symptom recurrence and were asked to undergo one elective follow-up endoscopy. The follow-up period lasted until the end of the study in 1995.

\section{Definition of Ulcer Recurrence}

Peptic ulcer relapse was defined as endoscopically confirmed recurrent peptic ulcer after endoscopically proven healing of the initial ulcer. By definition, superficial erosions were not considered to be ulcers.

\section{Results}

Two hundred forty-seven patients (183 patients with duodenal ulcers and 64 patients with gastric ulcers) were enrolled. $H$. pylori infection was cured in 186 of 247 patients $(75 \%)$. These $186 \mathrm{H}$. pylori-negative patients underwent endoscopy every 3 months in the first year

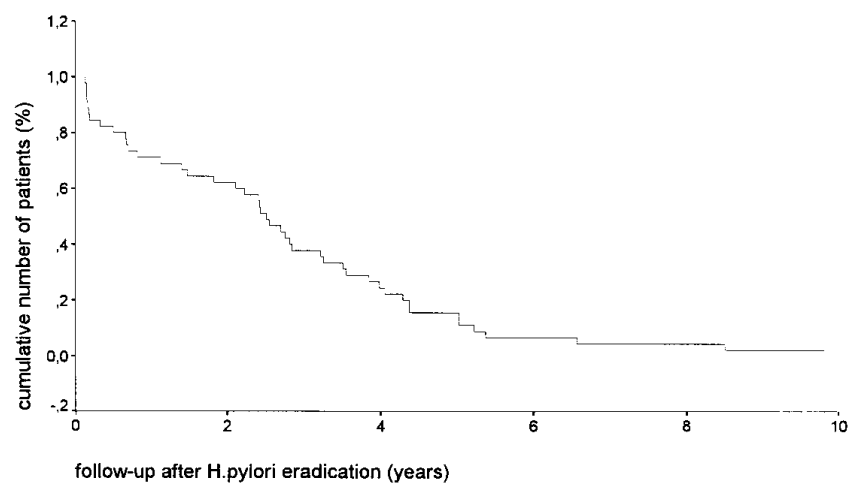

Figure 2. Cumulative number of patients with gastric ulcers per year of follow-up after apparently successful $H$. pylori eradication. 
Table 1. Demography and Clinical Outcome of Patients With Duodenal and Gastric Ulcer Disease

\begin{tabular}{|c|c|c|}
\hline & $\begin{array}{l}\text { Duodenal ulcer } \\
\text { disease }\end{array}$ & $\begin{array}{c}\text { Gastric ulcer } \\
\text { disease }\end{array}$ \\
\hline Included patients $(n)$ & 183 & 64 \\
\hline Mean age, $y r$ (range) & $48.2(23.2-85.9)$ & $54.0(29.5-78.2)$ \\
\hline Sex: M/F (\%/\%) & $118 / 65(64.5 / 35.5)$ & $42 / 22(65.5 / 34.4)$ \\
\hline \multicolumn{3}{|l|}{ Successful $H$. pylori } \\
\hline $\begin{array}{l}\text { Follow-up after H. pylor } \\
\text { eradication, } y r \\
\text { (range) }\end{array}$ & $2.6(0.6-9.2)$ & $2.5(0.5-9.8)$ \\
\hline \multicolumn{3}{|l|}{ Patient-years after } \\
\hline H. pylori eradication & 367 & 113 \\
\hline Ulcer relapse rate $(n)$ & 0 & 0 \\
\hline
\end{tabular}

NOTE. Demography and clinical outcome of patients with endoscopically proven duodenal or gastric ulcer disease. Patients in whom $H$. pylori was successfully eradicated were subjected to long-term follow-up for up to 9.8 years. Patients who underwent maintenance treatment with $\mathrm{H}_{2} \mathrm{RA}$ or NSAIDs or patients with carcinoma were excluded.

after documented ulcer healing. Demographic characteristics and clinical outcome are summarized in Table 1.

After the first year of follow-up, 96 patients (64 with duodenal ulcers and 32 with gastric ulcers) remained available for scheduled half-yearly endoscopies. The remaining 89 patients ( 74 with duodenal ulcers and 15 with gastric ulcers) who declined repetitive elective follow-up endoscopy were monitored for recurring symptoms and received requests for follow-up endoscopy in 1995. Sixty-one of them underwent follow-up endoscopy in 1995, whereas 28 (24 with duodenal ulcers and 4 with gastric ulcers) refused to do so. These 28 patients had documented cure of the infection at the end of the first year of follow-up after successful $H$. pylori eradication and had no recurrent symptoms through the end of follow-up.

Outcomes of patients with duodenal ulcers. $H$. pylori eradication was successful in 141 of 183 patients with duodenal ulcer disease. None had a duodenal ulcer relapse. The median follow-up period after successful $H$. pylori eradication in these patients was 2.6 years, ranging from 0.6 to 9.2 years, corresponding to 367 patientyears.

Outcomes of patients with gastric ulcers. $H$. $p y$ lori eradication was successful in 45 of 64 patients with gastric ulcer disease. None had a recurrent gastric ulcer. The median $H$. pylori-negative follow-up period in these patients was 2.5 years, ranging from 0.5 to 9.8 years, corresponding to 113 patient-years.

\section{Discussion}

This is the first prospective long-term study showing complete absence of relapse of duodenal or gastric ulcers after successful eradication of $H$. pylori for a maxi- mum of 9.8 years in patients not using aspirin or NSAIDs.

$H$. pylori infection is associated with recurrence of duodenal and gastric ulcers as confirmed by a large body of literature that also stresses that ulcer recurrence is less frequent after its eradication after, on average, 1 year of follow-up. ${ }^{2,3}$ Combined data from 30 pilot and controlled studies show an overall duodenal ulcer relapse rate of $61 \%$ (range, 20\%-100\%) in patients who remain $H$. pylori positive compared with $3 \%$ (range, $0 \%-22 \%$ ) in patients free of $H$. pylori. ${ }^{2,3}$ A few studies have reported gastric ulcer relapse rate in relation to $H$. pylori status, ${ }^{2,20-24}$ with a mean follow-up period of 9 months (range, 3-12 months). Gastric ulcers relapsed on average in 52\% of patients who remained $H$. pylori positive compared with $2 \%$ of the cured patients. ${ }^{2,3}$ Only two studies have followed up on patients after healing of duodenal or gastric ulcer for a prolonged period. ${ }^{30,31}$ Forbes et al. ${ }^{30}$ reported on follow-up for 7 years (mean, 6.5 years; range, $5.1-7.6$ years), but $37 \%$ of their patients were lost before final follow-up endoscopy. The duodenal ulcer relapse rate in $H$. pylori-positive patients was $20 \%$ compared with $3 \%$ in $H$. pylori-negative patients. Interpretation of the relapse rates, however, is hampered by the fact that H. pylori was assessed by "clearance" and not "eradication" of H. pylori.

For 4 years Labenz et al. ${ }^{31}$ followed up on 190 patients with duodenal ulcers after $H$. pylori eradication by annual endoscopy, or when patients were symptomatic, and found a mean annual duodenal ulcer relapse rate of $0.9 \%$ per patient-year and concomitant reinfection after successful eradication of $H$. pylori. Because no DNA fingerprinting of the isolated $H$. pylori strains was performed, it remains speculative whether these recurrent infections were due to a new $H$. pylori infection or recrudescence. The incidence of apparent new infections, however, is higher compared with the natural acquisition rate of the infection, which is reported to be approximately $0.3 \%$ in the Western world. ${ }^{33}$ This indicates the possibility of recrudescence rather than reinfection. Moreover, Bell and Powell's study indicates that the majority of $H$. pylori reinfections occur in the first 12 months of follow-up after apparent $H$. pylori eradication, a period in which recrudescence is to be expected. ${ }^{34}$ In our study, duodenal as well as gastric ulcer relapses did not occur in the $H$. pylori-eradicated patients even after follow-up for up to 9.8 years. We did not observe reinfection in any of these patients. The absence of recurrence of $H$. pylori infection after apparent successful eradication is in agreement with the results of our reinfection study, which includes a substantial number of nonulcer patients. ${ }^{35}$ Reoccurrence of $H$. pylori infection was proved in 9 of 173 cured pa- 
tients. Two patients had an iatrogenically transmitted reinfection with $H$. pylori, as classified by DNA analysis of pre-eradication and posteradication strains. Recrudescence of $H$. pylori infection was likely in 6 of 7 patients (identical DNA pattern pre-eradication and posteradication). Reoccurrence of $H$. pylori infection in 1 patient could not be classified because the pre-eradication strain was lost.

All the patients with reoccurrence of $H$. pylori infection had functional dyspepsia at study entry, and no ulcer was noticed by repeated endoscopies during follow-up. It is obvious that persistent or recrudescent $H$. pylori infection, despite attempted $H$. pylori eradication, is accompanied by recurrence of initially healed ulcers (data not shown). Studies of relapse rates of duodenal or gastric ulcers are complicated by several additional possible confounders. The loss of patients and the sometimes retrospective character may lead to patient selection bias. ${ }^{3}$ Because $H$. pylori infection is associated with ulcer disease, the ulcer relapses will also be related to recurrent infection. ${ }^{1,10}$ It is therefore crucial that $H$. pylori eradication is documented accurately. Most of the studies report ulcer relapse rates $(1 \%-22 \%)$ despite the apparent absence of $H$. pylori infection after eradication therapy. ${ }^{5-31}$ However, in several of these studies, it is obvious that "clearance" of $H$. pylori infection rather than "eradication" was used to assess cure of the infection. These studies report, as expected, higher ulcer relapse rates during presumed " $H$. pylori-negative" follow-up, ranging from $3 \%$ to $22 \%$. $5,9,12,21,30$

Our study outcome contrasts with those of the aforementioned studies, with the difference probably caused by the assessment of cure of $H$. pylori infection undertaken at least 4 weeks after the cessation of $H$. pylori eradication therapy using two different methods (culture and histology). These procedures may have avoided falsenegative $H$. pylori assessments. ${ }^{32}$

H. pylori eradication therapy may have been less effective in the early studies. ${ }^{24,36}$ Using these less effective H. pylori eradication regimens, apparent reinfection may occur even after 1 year of follow-up, ${ }^{24}$ which, as expected, is associated with ulcer recurrence. ${ }^{5,9,10}$ Because in most studies of duodenal ulcer, relapse patients were followed up for up to 12 months, ${ }^{5-9,11,16,20,22,25}$ some of the ulcer relapses may be explained by late recrudescence of $H$. pylori infection. In our study, less effective therapies were also used in the early phase; however, because the followup period was for more than 1 year, and because of detailed assessment of the eradication of $H$. pylori infection, it was finally possible to show that no $H$. pylori reinfection had taken place, and, therefore, in cases of documented, successful $H$. pylori eradication, no recurrence of ulcers occurred.
Interpretation of ulcer-relapse data is even more difficult for studies reporting on ulcer recurrence without relating to the current $H$. pylori status. ${ }^{18,22,23}$ Furthermore, patients should only be included in ulcer-relapse follow-up studies after endoscopic proof of healing of the initial ulcer. Patients with inactive ulcer ${ }^{16}$ or functional dyspepsia ${ }^{10}$ should be excluded.

Nevertheless, studies performed with appropriate diagnostic accuracy still report $H$. pylori-negative ulcer relapses. ${ }^{6-8,11,12,18,22,25,27,29,31}$ In these cases, the (occult) use of aspirin or NSAIDs may account for recurrent ulcers in the absence of $\mathrm{H}$. pylori infection. ${ }^{34} \mathrm{~A}_{\text {recent review }}{ }^{3}$ reported that NSAID use has been excluded in only one study. ${ }^{20}$ The exclusion of patients using NSAIDs or aspirin is probably the other important reason for the complete absence of ulcer relapses in our study.

Published studies on gastric ulcer relapse are scarce, and the follow-up periods do not exceed 12 months. ${ }^{25-29}$ In our study, patients with gastric ulcers were followed for up to 9.8 years after $H$. pylori eradication. The difference in outcome on ulcer relapse rates between our study and other published studies is probably mainly related to the fact that we vigorously excluded patients on NSAID or aspirin therapy. If, after exclusion of these confounders, $H$. pylori-negative duodenal or gastric ulcers remain, other rare causes, such as Crohn's disease and Zollinger-Ellison syndrome, should be excluded. ${ }^{36-38}$

In conclusion, relapses of duodenal or gastric ulcers remain absent after true eradication of $H$. pylori, even after follow-up of up to 9.8 years. Eradication of $H$. pylori should therefore become mandatory treatment for both duodenal and gastric ulcer disease. Ulcer disease that has been lifelong and recurrent, possibly accompanied by potentially life-threatening complications, can be cured definitively once its causative agent, H. pylori, has been eradicated.

\section{References}

1. Rauws EAJ, Langenberg W, Houthoff HJ, Zanen HC, Tytgat GNJ. Campylobacter pylori disassociated chronic antral gastritis. Gastroenterology 1988;94:33-40.

2. Van der Hulst RWM, Tytgat GNJ. Helicobacter pylori and peptic ulcer disease. Scand J Gastroenterol 1996; 31(Suppl 220):1018.

3. Hopkins RJ, Girardi LS, Turney EA. Relationship between Helicobacter pylori eradication and reduced duodenal and gastric ulcer recurrence: a review. Gastroenterology 1996;110:1244-1252.

4. National Institutes of Health Consensus Development Conference. Helicobacter pylori in peptic ulcer disease. JAMA 1994; 272:65-69.

5. Marshall BJ, Goodwin CS, Warren JR, Murray R, Blincow ED, Blackbourn SJ, Phillips M, Waters TE, Sanderson CR. Prospective double-blind trial of duodenal ulcer relapse after eradication of Campylobacter pylori. Lancet 1988; 2:1437-1442.

6. Graham DY, Lew GM, Evans DG, Evans DJ, Klein PD. Effects of 
triple therapy (antibiotics plus bismuth) on duodenal ulcer healing. A randomized controlled trial. Ann Intern Med 1991;115: 266-269.

7. Mannes GA, Bayerdörffer E, Höchter W, Weingast J, Heldwein W, Sommer A, Muller-Kosseur S, Bornschein W, Weinzieri M, Ruchderschel G, Blendinger C, von Wueffer H, Kopcke W, Stolte M. Decreased relapse rate after antibacterial treatment of Helicobacter pylori-associated duodenal ulcers. Munich Duodenal UIcer Trial. Eur J Gastroenterol Hepatol 1993;5:145-153.

8. Hentschell E, Brandstätter G, Dragosics B, Hirschl AM, Nemec $\mathrm{H}$, Taufer $\mathrm{M}$, Wurzer $\mathrm{H}$. Effect of ranitidine and amoxicillin plus metronidazole on the eradication of Helicobacter pylori and the recurrence of duodenal ulcer. N Engl J Med 1993;312:308-312.

9. Coghlan JG, Humphries H, Dooley C, Keane C, Gilligan D, McKenna D, et al. Campylobacter pylori and recurrence of duodenal ulcers: a 12-month follow-up study. Lancet 1987;2:1109-1111.

10. Borody TJ, Cole P, Noonan S, Morgan A, Lenne J, Hyland L, et al. Recurrence of duodenal ulcer and Campylobacter pylori infection after eradication. Med J Aust 1989;151:431-435.

11. Rauws EAJ, Tytgat GNJ: Eradication of Helicobacter pylori cures duodenal ulcer disease. Lancet 1990;1:1233-1235.

12. Blum AL, Armstrong D, Dammann H, Fischer M, Greiner L, Haase W, et al. The effect of Helicobacter pylori on the healing and relapse of duodenal ulcer (abstr). Gastroenterology 1990;98: A22.

13. Carrick J, Daskalopoulos G, Mitchell H, Lee A. Successful eradication of $H$. pylori infection prevents recurrence of duodenal ulceration (abstr). Rev Esp Enferm Dig 1990; 78(Suppl 1):122- 123.

14. Fiocca R, Solcia E, Santoro B. Duodenal ulcer relapse after eradication of Helicobacter pylori (letter). Lancet 1991;337:1614.

15. Coelho LGV, Passos MCF, Chausson Y, Costa EL, Maia AF, Brandao MJ, Rodrigues DC, Castro CP. Duodenal ulcer and eradication of Helicobacter pylori in a developing country. An 18-month follow-up study. Scand J Gastroenterol 1992;27:362-366.

16. Seppälä K, Färkkilä M, Nuutinen H, Hakala K, Vaananen H, Rautelin H, Kosunen TU. Triple therapy of Helicobacter pylori infection in peptic ulcer. A 12-month follow-up study of 93 patients. Scand J Gastroenterol 1992;27:973-976.

17. Unge $P$, Gad A, Erikkson K, Bergman B, Carling L, Ekstrom P, Glise H, Gnarpe H, Junhadd D, Lindholmer C, Sandzen B, Strandberg L, Stubberod H, Weywadt L. Amoxicillin added to omeprazole prevents relapse in the treatment of duodenal ulcer patients. Eur J Gastroenterol Hepatol 1993;5:325-331.

18. Sung JJ, Chung SCS, Ling TKW, Yung MY, Cheng AF, Hosking SW, Li AK. One-year follow-up of duodenal ulcers after 1-week triple therapy for Helicobacter pylori. Am J Gastroenterol 1994; 89:199-202.

19. Mantzaris CJ, Hatzis A, Tamvakologos G, Petraki K, Spilades C, Triadaphyllou G. Prospective, randomized, investigator-blind trial of Helicobacter pylori infection treatment in patients with refractory duodenal ulcers. Healing and long-term relapse rates. Dig Dis Sci 1993;36:1132-1136.

20. McCarthy CM, Collins R, Beattie S, Hamilton H, O'Morain C. Treatment of Helicobacter pylori-associated duodenal ulcer with omeprazole plus antibiotics. Aliment Pharmacol Ther 1993; 7 : 463-466.

21. Rune S, Justensen T, Hansen JM, Jensen TG, Eriksen J, Thomsen OO, et al. Prevention of duodenal ulcer recurrence with penicillin: a double blind placebo-controlled trial. Scand J Gastroenterol 1993; 28:438-442.

22. Solcia E, Villani L, Fiocca R, Luinetti O, Bolorini R, Trespi E, Perego M, Alvisi C, Lazzaroni M, Bianchi Porro G. Effects of eradication of Helicobacter pylori on gastritis in duodenal ulcer patients. Scand J Gastroenterol 1994;29:28-34.

23. Collins R. Beattie S, O'Morain C. Long-term evaluation of anti-
Helicobacter pylori treatment in duodenal ulcer: monotherapy versus combination therapy (abstr). Gastroenterology 1991;100: A48.

24. Bell GD, Powell KU, Burridge SM, Harrison G, Rameh B, Weil J, Gant PW, Jones PH, Trowell JE. Reinfection or recrudescence after apparently successful eradication of Helicobacter pylori infection: implications for treatment of patients with duodenal ulcer disease. Q J Med 1993;86:375-382.

25. Sung JJ, Sydney SC, Ling ThKW, Yung MY, Leung VK, Ng EK, Li $\mathrm{MK}$, Cheng AF, Li AK. Antibacterial treatment of gastric ulcers associated with Helicobacter pylori. N Engl J Med 1995;332: 139-142.

26. Tatsuta M, Ishikawa H, lishi H, Okuda S, Yokota Y. Reduction of gastric ulcer recurrence after suppression of Helicobacter pylori by cefixime. Gut 1990;31:973-976.

27. Seppälä K, Pikkarainen P, Karvonen AL, Gormsen H, Finnish Gastric Ulcer Study Group (FGUSG). The role of Helicobacter pylori eradication, the gastric ulcer healing and relapse (abstr). Gastroenterology 1992;102:A162.

28. Bayerdörffer E, Mannes GA, Höchter W, Weingart J, Sommer A, Klann $\mathrm{H}$, et al. Antibacterial treatment of gastric ulcers. German gastric ulcer study (abstr). Gastroenterology 1993;104:A40.

29. Labenz J, Borsch G. Evidence of the essential role of Helicobacter pylori in gastric ulcer disease. Gut 1994;35:19-22.

30. Forbes GM, Glaser ME, Cullen DJE, Warren JR, Christiansen KJ, Marshall BJ, Collins BJ. Duodenal ulcer treated with Helicobacter pylori eradication: seven year follow-up. Lancet 1994;343:258260.

31. Labenz J, Borsch G. Highly significant change of the clinical course of relapsing and complicated peptic ulcer disease after cure of Helicobacter pylori infection. Am J Gastroenterol 1994; 89:1785-1788.

32. Van der Hulst RWM, Verheul SB, Weel JFL, Gerrits Y, ten Kate FJW, Dankert J, Tytgat GNJ. Effect of specimen collection techniques, transport media, and incubation of cultures on the detection rate of Helicobacter pylori. Eur J Clin Microbiol Infect Dis 1996;15:211-215.

33. Kuipers EJ, Pena AS, van Kamp G, Uyterlinde AM, Pals G, Pels NFM, Meuwissen SG. Seroconversion of Helicobacter pylori. Lancet 1993;342:328-331.

34. Bell GD, Powell KU. Helicobacter pylori reinfection after apparent eradication: the Ipswich experience. Scand J Gastroenterol 1996; (Suppl)215:96-104.

35. van der Hulst RWM, Rauws EAJ, Köych B, Keller JJ, ten Kate FJW, Dankert J, Tytgat GNJ, Van der Ende A. H. pylori reinfection is virtually absent after successful eradication. J Infect Dis 1997; 176:196-200.

36. Xia HX, Gilvarry J, Beattie S, Hamilton H, Keane CT, Sweeney $\mathrm{EC}$, et al. Recrudescence of Helicobacter pylori infection in patients with healed duodenal ulcer after treatment with different regimens. Am J Gastroenterol 1995;90:1221-1225.

37. McColl KEL, El-Nujumi AM, Chittajallu RS, Dahill SW, Dorrian C, el Omar E, et al. A study of the pathogenesis of Helicobacter pylori-negative chronic duodenal ulcer disease. Gut 1993;34: 762-769.

38. Borody TJ, George LL, Brandl S, Andrews P, Ostapowicz N, Hyland L, Devine M. Helicobacter pylori-negative duodenal ulcer. Am J Gastroenterol 1991;86:1154-1157.

Received December 24, 1996. Accepted June 23, 1997.

Address requests for reprints to: René W. M. van der Hulst, M.D., Ph.D., Department of Gastroenterology, Academic Medical Center, Meibergdreef 9, 1105 AZ Amsterdam, The Netherlands. Fax: (31) 20-691-7033. 